

\title{
Editorial
}

\section{The conundrum of defining paramedicine: more than just}

\section{what paramedics 'do'}

\author{
David Long PhD, Paramedic Academic and Clinical Placement Unit Coordinator ${ }^{1}$; Jakki Lea DipParaSc(Amb), is \\ Paramedic Academic ${ }^{1}$; Scott Devenish BN, DipParaSc, MVEdT, PhD, Fellow ${ }^{1}$
}

\section{Affiliation:}

${ }^{1}$ School of Clinical Sciences, Faculty of Health, Queensland University of Technology

The term 'paramedicine' at first glance is deceptively simple. After all, paramedicine is an ever-increasing part of the lexicon in numerous ambulance services and stakeholder organisations across the globe. However, it is unclear if a consensus exists on the definition of paramedicine that transects international boundaries. A lack of consensus is unsurprising given the rapid evolution of our profession, fundamentally changing both professional and clinical boundaries. The impetus for change is multifactorial, although it is clear that paramedics are increasingly seen as an integral component of the healthcare continuum (1).

An international consensus on the definition of paramedicine has important implications for the profession. Perhaps most significantly, it offers an assertive voice in establishing paramedicine as a unique discipline within healthcare. Whether policy makers formally recognise paramedics as health professionals is a matter of debate (2). However, in gaining a consensus in the definition of paramedicine, the comprising principles and attributes become less opaque. In this way, the journey towards professionalisation can be navigated more efficiently through a coordinated approach across national and international borders.

Surprisingly, few notable attempts at defining paramedicine have been offered by peak industry and representative bodies worldwide including the National Emergency Medical Services Management Association from the United States (3) and a report on the self-regulation of paramedics in Manitoba, Canada (4). In Australia, formative works around competency standards for the profession $(5,6)$ and paramedic role descriptors $(7)$ have been published, yet a clearly articulated definition of paramedicine is elusive. Furthermore, the College of Paramedics in the United Kingdom appear to distance themselves altogether from the term 'paramedicine' (8) raising the spectre that the term does not adequately reflect the discipline.

The apparent lassitude in defining paramedicine is also evident in the peer-reviewed literature. While the issue of confusing nomenclature in paramedicine has been recognised previously (9), a recent article published in this journal by Bowles, van Beek and Anderson (10) provides the most authoritative examination to date of what term(s) best describe the profession. The authors conducted a study on the conceptualisation of paramedic practice, but were limited to a mostly provincial context in Canada. Nevertheless, the authors rightly argued their findings can be used as a framework to better understand traditional and evolving roles in the paramedic profession.

The challenge to define paramedicine should not be underestimated. For example, the definition should describe effectively paramedics working within both 'traditional' and emerging models of care; be relevant across national and international boundaries; be adaptable to allow for the future growth of the profession; and articulate the attributes that allow paramedics to stand apart from other cognate health disciplines, such as nursing. Ultimately, a consensus on a single definition of paramedicine may herald a 'coming of age' for an occupation to become a profession. 
Defining paramedicine in a concise and descriptive statement however, should not be confused with defining paramedicine as a profession. Indeed, a number of articles have been published in this journal dating back over a decade, canvassing the issue of professionalism and professionalisation in the paramedic discipline (11-14). This is not to say the issues of defining paramedicine and defining paramedicine as a profession are completely exclusive of each other. On the contrary, both issues are inexorably linked and complement the other. In this regard, the debate on defining paramedicine has already begun.

This editorial intends to stimulate a robust discussion to find an international consensus on the definition of paramedicine. Defining paramedicine is more than simply an exercise in explicating what a paramedic 'does'. Rather, a definition underscores the philosophical pillars on which paramedic practice is built and has implications in numerous domains such as paramedic role perception, education and service delivery. A definition of paramedicine reached through expert consensus can serve as a beacon to guide the profession towards a collective understanding that ultimately better meets the needs of the community we serve.

\section{References}

1. Catterall M. The role of paramedics with extended practice: exploring the healthcare context. Journal of Paramedic Practice 2012;4:569-75.

2. O'Meara P. Paramedics marching toward professionalism. Australasian Journal of Paramedicine 2009;7:(1).

3. National EMS Management Association. Call for common nomenclature for the profession of paramedicine 2017. Available at: www.nemsma.org/images/pdfs/Position-Paper-Paramedicine-Nomemclature-Final.pdf

4. Toews R. Consultant report on the implementation of self-regulation for paramedics 2017. Available at: www.gov.mb.ca/ health/rhpa/docs/paramedic_selfregulation.pdf

5. Paramedics Australasia. Australasian competency standards for paramedics 2011. Available at: https://paramedics.org/wpcontent/uploads/2016/09/PA_Australasian-Competency-Standards-for-paramedics_July-20111.pdf

6. The Council of Ambulance Authorities. Professional competency standards 2013. Available at: http://caa.net.au/ caanet/ images/documents/accreditation_resources/Paramedic_Professional_Competency_Standards_V2.2_February_2013_ PEPAS.pdf

7. Paramedics Australasia. Paramedicine role descriptions. Paramedics Australasia; 2009. Available at: www.paramedics.org/ content/2009/07/PRD_211212_WEBONLY.pdf

8. College of Paramedics. Paramedic career framework, 3rd edn, 2015. Available at: www.collegeofparamedics.co.uk/ downloads/Post-Reg_Career_Framework_3rd_Edition.pdf

9. Long D, Clark M, Lim D, Devenish S. What's in a name? The confusion in nomenclature of low-acuity specialist roles in paramedicine. Australasian Journal of Paramedicine 2016;13:(3).

10. Bowles R, van Beek C, Anderson G. Four dimensions of paramedic practice in Canada: defining and describing the profession. ibid. 2017;14(3).

11. Johnston T, Acker J. Using a sociological approach to answering questions about paramedic professionalism and identity. Australasian Journal of Paramedicine. 2016;13(1).

12. Williams B, Brown T, Onsman A. From stretcher-bearer to paramedic: the Australian paramedics' move towards professionalisation. Australasian Journal of Paramedicine 2012;7(4).

13. Williams B, Brown T. Is the Australian paramedic discipline a full profession? Australasian Journal of Paramedicine 2010;8(1).

14. Reynolds L. Is prehospital care really a profession? Australasian Journal of Paramedicine 2004;2(1). 